2006-2475: BUILDING A WATER TOWER AND LEARNING ABOUT A ROLE FOR SERVICE LEARNING IN THE CIVIL ENGINEERING CURRICULUM

Enos Inniss, University of Texas-San Antonio

Leslie Inniss, Florida A\&M University 


\title{
Building a Water Tower and Learning about a Role for Service Learning in the Civil Engineering Curriculum
}

\begin{abstract}
Service learning is loosely defined as student participation in activities designed to serve a member of the community in a capacity that has a strong relationship to information presented in a particular class or in classes. Based on the experience of having students build a water tower for a museum exhibit, the question of the role of service in the civil engineering (CE) curriculum was explored. Service learning projects such as this one are contrasted to the steel bridge and concrete canoe projects done as part of the ASCE student competitions. This paper aims to consider the development and management of a service learning project for the civil engineering curriculum. Several example projects are listed along with their relation to various civil engineering courses. Additionally management suggestions are presented. Success of the project for both the students and the client depends on the number of students involved, on the investment of the client in the project, and on the level of the corresponding CE course. The possibility of extending the project over several semesters and therefore through the curriculum is explored.
\end{abstract}

\section{Introduction}

As we become a more global and multicultural society we need educated workers who can meet the challenges of a rapidly-changing world. One way to ensure this type of worker is to train university students, not only in the classroom, but also in the real world. Service learning is one means of providing this type of education, particularly in engineering. If we define engineering as an applied science designed to solve practical problems and thereby improve community living, then service learning is crucial to engineering education. ABET's recent changes in operating philosophy seems to reflect this realization. In its criteria for Civil Engineering Programs, ABET calls for curriculum that allows students "to perform civil engineering design by means of design experiences integrated throughout the professional component of the curriculum."1

Although there is not a single, universal definition of service learning, the National ServiceLearning Clearinghouse suggests that all the diverse definitions have a core concept, namely that "service learning combines service objectives with learning objectives with the intent that the activity changes both the recipient and the provider of the service. This is accomplished by combining service tasks with structured opportunities that link the task to self-reflection, selfdiscovery, and the acquisition and comprehension of values, skills, and knowledge content."2 In terms of service learning in higher education, Bringle and Hatcher suggest that it is "a creditbearing educational experience in which students participate in an organized service activity that meets identified community needs and reflect on the service activity in such a way as to gain further understanding of course content, a broader appreciation of the discipline, and an enhanced sense of civic responsibility." "According to the National Service-Learning Clearinghouse, during the 1999-2000 academic years at least 712,000 students on 349 campuses had participated in some form of service. Similarly, since the 1990s, service learning has been gaining acceptance as an instructional tool in engineering education. ${ }^{4}$ 
Just as with general service learning, service learning in engineering has been defined in several different ways:

$>$ A form of experiential learning that integrates classroom concepts with related community service.

$>$ An educational philosophy that promotes active learning through community service.

$>$ An educational experience that enables students to apply material learned in the classroom by volunteering in a real-world situation.

$>$ A pedagogical strategy that combines community service with classroom learning.

$>$ A form of experiential education in which students meet the learning objectives of a course by working with a community partner.

$>$ A pedagogy that integrates academic learning with community-based work.

All of these definitions convey the idea that service learning allows the university to provide benefits to the community in which it is located while educating the students which it serves. Service learning is thus viewed as a form of experiential learning where course-based concepts are reinforced in community settings which benefit from student involvement.

Vaughn and Seifer suggest that "engineering is uniquely situated for the integration of service learning in the curriculum because of its emphasis on experiential education, problem solving, and working in groups." Similarly, Pritchard, opines that "service learning engineering may be especially promising" given ABET's EC 2000's “major design experience" requirement. ${ }^{6}$

Further illustrating the importance of service learning in engineering education is a recent ad in The Chronicle of Higher Education for an environmental and civil engineering assistant/associate professor that states, "Interest in collaborative and problem-based learning and service learning are highly valued characteristics.",

Several papers address the actual implementation of service learning in the engineering curriculum. Namely, Piechota ad Nambisan provide excellent examples of how service learning can be integrated into junior and senior level civil and environmental engineering courses ${ }^{8}$. Similarly, Saviz describes the value of incorporating service learning in an upper-division civil engineering course. ${ }^{9}$ Brackin and Gibson discuss the importance of reflection when implementing service learning into the capstone course in mechanical engineering. ${ }^{10}$ Additionally, Bullard et al summarize the challenges encountered in implementing a service learning component in a chemical engineering course. ${ }^{11}$

In this paper we describe the process of establishing and managing this pilot service learning project using civil engineering students at a large southwestern university. Because the university has not yet mandated service learning requirements in its civil engineering program, the project was presented to the students as one of several options for extracurricular experience. Subjective student and community client evaluations are used to illustrate the perceived benefits of the project. Finally, we use the experience to advocate opportunities for service learning projects to be included as part of the civil engineering curriculum.

\section{Description of Project and Timeline}

The overall goals of the Witte Water Tower Project were to design and construct a water tower to demonstrate the lifting of water. Following numerous meetings between interested students, 
the lead author and the client, the students and the client agreed on having the final product be a shortened water tower in appearance and one that operates to demonstrate to visitors the effort needed to lift water. For the latter purpose, four hand pumps (placed on the perimeter of the tower base) are used to lift water up four standpipes located near the central stem of the water tower. (see figure 1)

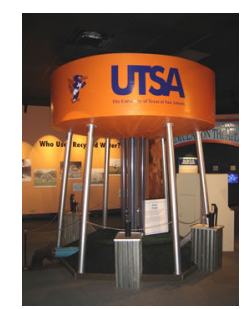

Figure 1: Actual Water Tower in the World of Water Exhibit

As with any service learning project, it cannot be completed overnight. For the lead author, a brainstorming session with a community partner regarding the feasibility of a museum exhibit became the basis for a service learning project. The timeline for the Witte Water Tower Project is outlined below:

September 2003 - Dr. Enos C. Inniss and Dr. Weldon Hammond, director of the Center for Water Research were invited to a Water Resource Center meeting to help the staff of the Witte Museum brainstorm ideas for the Witte Water Works exhibit (a two phase project which was first planned as a prototype to evaluate project ideas to be displayed during the spring and summer of 2005 and then a full Resource Center for be completed by 2007).

March 2004 - Dr. E.C. Inniss is contacted by the Director of Infrastructure Planning at the San Antonio Water System (SAWS) inquiring about whether University of Texas at San Antonio (UTSA) students might be interested in helping with the design of a model of the SAWS water and wastewater system. The SAWS contact was unrelated to introductions made at the September Witte meeting, but rather related to a research project done with SAWS.

June 2004 - Initial SAWS-Witte planning meeting to determine what aspects of the prototype exhibit SAWS will contribute to and how UTSA would help with those.

July 2004 - Students recruited to participate with the Witte project.

August 2004 - Second planning meeting with the members of SAWS. This meeting kicked off monthly meetings with either SAWS or Witte or both during the entire Fall term (September, October, November). The exhibit expected to include a cutaway of a home showing water infrastructure, a water tower/elevated storage tank, a computer system (SCADA) that controls water flow through the city, and some understanding of how water gets from the aquifer to a home. Primary focus of UTSA students was to develop a working water tower. Specifically, students are required to determine how it will look and how it will operate. 
September 2004 - Students began to brainstorm ideas for carrying out the designs and touring several areas to get a better idea of what they need to imitate for the exhibit. At $3^{\text {rd }}$ client meeting, UTSA places focus solely on the water tower.

October 2004 - At $4^{\text {th }}$ client meeting students deliver model of water tower, provide preliminary design schematics, and cost estimates of materials needed for construction.

November 2004 - At $5^{\text {th }}$ client meeting, client asks students if they can actually construct the working water tower for the exhibit.

January 2005 - Timeline for construction settled and construction begins on actual water tower.

February 2005 - Water tower completed and delivered to the Witte Museum.

Both the elements of the project, the deliverables, and the assigned roles provided learning experiences for the students that are not available in the typical classroom setting.

The elements of this service-learning project included:

$>$ The Design Exercise

> The Construction Exercise (These allowed students to review shortcomings of the design, to troubleshoot the construction of the full system, and to truly incorporate the review process of the problem solving method.)

$>$ Client meetings

$>$ Student planning and construction meetings

Deliverables included: (These allowed students to earn an appreciation for the process and the various roles required to fully complete a project.)

$>$ Design schematics

$>$ A materials list

$>$ A model of the full-scale structure

$>$ The full-scale, "working" water tower

Assigned Roles:

$>$ Faculty - served as advisor to the students (and at times to the client), liaison between the students and client, and facilitator for helping to move the project to completion

$>$ Students/Participants - took charge of various aspects of the project. Each had a lead in some aspect of the design and construction

$>$ Client - dictated what the desired outcome was and provided feedback on progress and product. (Having the museum as an initial partner was excellent in helping to develop ground rules on how such a project should be handled)

\section{Participants}

When the lead author first discussed the project with the participants, it was presented as a project independent from classes and described as a volunteer project to which no academic credit would be awarded, but one which would provide invaluable hands-on experience. All 
students solicited were at least juniors in the program and had completed at least fluid mechanics and environmental engineering.

Originally, the scope of the project included a treatment process, a water tower, an interactive computer program, and information about careers and people in the water industry. The treatment process was going to be a potential working model, the water tower a potential working model, and the computer program was supposed to demonstrate the controllability of the water system (a SCADA system).

After the lead author met with the Witte group and again discussed the scope of UTSA's participation, the time the students were willing to devote to the project and the priority of pieces in the case where everything could not be delivered in the rather aggressive timeline the client set. The result was that the water tower was at the top of the priority list. The project duration was two months of planning in the fall semester and three months of construction and delivery in the spring semester.

Ten students expressed and interest in participating in the project. Subsequently, the whole group toured the SCADA system at the San Antonio Water System and then brainstormed how to scale for a museum exhibit.

Of the ten students who originally expressed interest in the project, four (4) students (or 1 team) actively participated in the Water Tower Project and delivered the tower to the client. Of the four who completed the project, two were graduating seniors, the third was in his senior year, and the remaining one was a second semester junior. Each had previously worked on student competition projects sponsored by ASCE (the American Society of Civil Engineers); two on steel bridge; one on concrete canoe; and one on timber bridge. All were interested in doing something slightly different. These four students were ultimately responsible for delivering the working tower, although the faculty member prompted the students to stay on task, at times at the request of the client. These students were asked to evaluate their experience including a listing of the classes to which the project related. Most agreed that the experience was one that enhanced their academic experience and they appreciated the client's investment and the variety of experiences.

At the same time, several potential snags were identified, namely budget/costs of completing and maintaining the project, the students own lack of experience in projects of this type, and the physical testing of equipment or equipment choices based on calculations. (For a copy of the students' evaluation of the project, see Appendix A).

Those who dropped out of the project either had time constraints or were more interested in the other aspects of the project when it was originally presented.

\section{Discussion}

Our experience with the Witte Water Tower Project offered several insights into service learning projects and their place in the engineering curriculum. Some of them are listed below.

Creating/establishing a project idea: Good service learning projects are a compromise between academic research and engineering application and should be structured in a way that the product can be accomplished in less than one semester, or within three to four months. 
In a classroom setting, the service learning project should be couched in similar class projects so that student participants are given the option of the service learning opportunity versus one of the other projects. The difference between the SL project and the others is primarily based on the use of a client as both a financial and interest resource. Once the project idea is established, then roles have to be assigned and understood. The faculty member(s) involved serve as advisors/facilitators for the project. They are tasked with being a liaison between the client and the students. Students are expected to be active participants in the project and therefore take charge of the various aspects of the project. It is best to try to have each student take a lead in some aspect of the design and/or construction. The client is responsible for dictating the outcome of the project as well as providing feedback on progress throughout the process of completion of the project. Solicitation of feedback from the client is a key to success of the project.

Establishing a student contingent: Two types of students are needed for a successful service learning project: leaders and workers. Leaders are students who are likely to push for the success of the project through interactions with both client and faculty, and keeping on top of deadlines and deliverables. Workers are students committed to active participation in the project completion. Participation on the project is completely voluntary. Opportunities for students to get off the project team should be available. If students are using the service learning experience as part of a class, then there should be an alternative way to have students earn that credit.

Interactions with client: It is extremely important to the project success to establish a working relationship with the client agency. The client should provide financial backing for project supplies and, in many cases, project ideas as well as feedback through the development and management of the project. The working relationship referred to here is one in which the client either approaches the department with project ideas or is receptive to proposed projects by faculty in the department.

Keeping up with deliverables: The students were expected to produce design schematics, a materials list, a model of the full-scale structure, and finally a full-scale, working water tower. Each of these deliverables was agreed upon by all involved and deadlines were set for each. The students were given primary responsibility for keeping up with the deadlines. The client maintained secondary responsibility by first communicating with the students directly via e-mail (copying the faculty member), and then, if there was a reasonable lack of response, with the faculty liaison to prompt student response. When there was an unforeseeable delay, then all parties met to revise the deadlines, with the students expected to present reasonable action to try to rectify missing a deadline(s). As a result, despite some delays earlier in the process, the water tower was delivered slightly ahead of schedule.

Understanding learning objectives: The learning objectives for these projects should be centered on providing the students with design experience directly tied to the course or courses being applied to the project as well as the construction experience. The latter construction experience establishes this type of project as extracurricular to what most students are doing as part of their typical academic training and compares favorably to the ASCE student competitions. It does not matter if the structure is simply a model or full-scale. However, it is important for the students to 
try to construct their own design.

Methods for measuring/assessing student understanding: Students are evaluated at the end of the experience on their feelings about project success and application of classroom concepts. The client was also evaluated on how well the product met the goals of the project. In addition to these end of the project evaluations, students may be assessed through quizzes and progress reports throughout the project on their understanding of various aspects of the tasks they are undertaking. These concurrent assessments would consider both concepts being applied and the process of the application. After the completion of the water tower project, it was decided that a more formal technical assessment was needed to better determine the effectiveness of the experience.

\section{Project Ideas for the CE Curriculum}

$>$ Water Resources: understanding of source water considerations, evaluation of design and performance of local storm water control measures

$>$ Geotechnical Engineering: understanding of soil types in the area and surveying the occurrence of foundation cracks in different areas of the community

$>$ Transportation Engineering: understanding of pavement types; evaluation of traffic flow patterns near university

\section{Conclusion}

This project, similar to the ASCE steel bridge and concrete canoe competitions, required first a design of the project with detailed drawings about what materials are needed and how these materials are to be placed in relation to each other. The second phase of this experience was the construction of an operational tower. This latter experience was more valuable for the students because it afforded them the opportunity to review shortcomings in the design, to troubleshoot construction of a full scale system, and to truly incorporate the review process of the problem solving method.

The choice of a real project versus an academic exercise depends on the constraints on the students' time and the demands of the project. When the students are given choices of opportunities there needs to be some equality in the expectations of the assignments themselves. Service learning here is considered the asking of questions whose answers are pertinent to a particular client, in most cases outside the university. In contrast, the other opportunities given are in the form of asking questions whose answers are pertinent to the university faculty, i.e., academic exercise.

The only contingency for having more students interested in the service learning project than available projects is to have "academic" projects as alternatives. Therefore, there are always sufficient projects for the students in the class. The credit does not differ from service learning to academic.

The following is a list of milestones for a successful service learning project.

1. Establish community service-learning partners.

2. Create a project ideas pipeline.

3. Create project idea summaries. 
4. Enlist student participation with a signed commitment sheet

5. Agree on deliverables and timeline.

6. Follow up on deadlines; Assess student progress

7. Submit product along with a final report.

8. Survey students and client on the success of the project and the application of course concepts.

Bibliography:

1 2005-2006 Criteria for Accrediting Engineering Programs

${ }^{2} \mathrm{http} / / /$ www.servicelearning.org/welcome_to_service-learning/service-learning_is/index.php

3 "Implementing service learning in higher education." 1996. Robert G. Bringle and Julie a. Hatcher. Journal of Higher Education, 67(2): March/April.

4 "Service learning in engineering." 2002. William Oakes, et al. 32 ${ }^{\text {nd }}$ ASEE/IEEE Frontiers in Education Conference; "ASEE and service learning". 2000. Edmund Tsang. Prism.

5 “Engineering education and service-learning." 2004. Rachel L. Vaughn and Sarena D. Seifer. Community-Campus Partnerships for Health, June.

6 "Service-learning and engineering ethics." 1999. Michael S. Pritchard. International Conference on Ethics in Engineering and Computer Science, March.

${ }^{7}$ The Chronicle of Higher Education, 8/15/2005

8 "Integration of Service Learning into Civil and Environmental Engineering Curriculum." 2005. Thomsa Piechota and Shashi Nambisan. Proceedings of the Annual Conference of the American Society for Engineering Education, Portland, OR.

9 "Work in Progress-Service Learning Opportunity: A University and Community Partnership in Creek Restoration.” Camilla M. Savitz, 2004. 34 ${ }^{\mathrm{TH}}$ ASEE/IEEE Frontiers in Education Conference. Savannah, GA.

10 “Service-Learning in Capstone Design Projects: Emphasizing Reflection.” 2004. Patricia Brackin and J. Darrell Gibson. Proceedings of the 2004 Annual Conference for Engineering Education.

11 "Service-Learning in CHE Senior Design. 2004. Lisa G. Bullard, Patti H. Clayton, and Steven W. Peretti. Proceedings of the 2004 Annual Conference for Engineering Education. 


\section{APPENDIX A: RESULTS OF STUDENT SURVEY EVALUATION \\ Student Survey}

Please complete the survey with responses to certain questions and ranking of various statements according to the following rubric:

(5) strongly agree; (4) agree; (3) can not be determined; (2) disagree; (1) strongly disagree

1. What classes, if any, did this project seem to expand upon?

Water and Wastewater Treatment (1); Construction Planning and Management (2); Engineering

Practice (2); Senior Design (3); Fluid Mechanics (2); Water Resources (1)

2. 545 Concepts learned in these classes were applied to the project.

3. $4 \quad 34$ The project helped you to better understand concepts presented in class.

4. What, if any, were some of these concepts referred to above?

- understanding water towers (purpose/operation); planning; cost estimating; designing it to work

- take charge of objectives; organize responsibilities; make sure everything worked

- water pressure; static pressure; water head; teamwork

5. 444 The time spent on the project was reasonable.

6. $\quad 5 \quad 5 \quad 4$ The client (the Witte Museum) was helpful in completion of the project.

7. $\quad \begin{array}{llll}5 & 5 & 4\end{array}$ The faculty liaison (Dr. Inniss) was helpful in completion of the project.

8. 454 The group worked well together.

9. 555 Each member of the group contributed to the success of the project.

10. 454 Experience on this project enhanced your academic experience.

11. 555 Similar hands-on experiences should be incorporated into the regular curriculum.

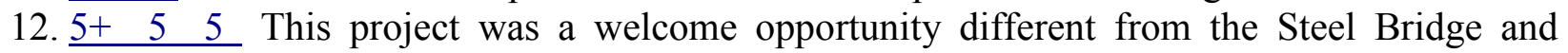
Concrete Canoe projects sponsored by ASCE.

13. 555 The experience of having to construct own design was useful in improving my approaches to design.

14. 255 The group was able to anticipate construction concerns as part of the initial project design.

15. 244 Project construction followed the conceptual design rather closely.

If not, what modifications were necessary to compete the construction?

- plumbing rerouting; connections at base of pump; tower legs/base connections

- during construction phase found certain things did not work as thought they would; found manufacturer information to not be reliable; found things needed that were not anticipated in design; did incorporate a contingency plan

- scale of the project had to be reduced to fit budget; poor quality pumps; no modeling/calculating done to test design 
From: Sam Edwards [utsa_stud@hotmail.com]

Sent: Wednesday, September 21, 2005 7:53 PM

To: Enos Inniss

Subject: RE: Survey of Experience with the Witte Water tower

Dr. Inniss,

It's good to hear from you. Attached is that survey. I'd like to let you know that beign involved with the Witte project really helped prepare me for what I'm doing now. I work in the municipal group for HDR Engineering in Dallas. I'm doing all kinds of things: meeting with clients, making field measurements, drawing project plan and profiles using Microstation \& AutoCAD, pulling quantities for construction estimates and writing report summaries. I've only been working here for 3 months! Completing that project at the Witte was the next best thing to having an internship and I think every student should have the opportunity to work with a real client on a real project (supervised of course by a professional who knows what common errors to look for when the student submits their design).

Hope your doing fine. I really enjoyed your classes and the time you spent preparing us for after college.

Sam Edwards 